\title{
A escolha profissional na perspectiva do estudante do ensino técnico de nível médio
}

\author{
Professional choice in the perspective of the high school technical
}

education student

\begin{abstract}
Nonato Assis de Miranda
Doutor em Educação pela Universidade Estadual de Campinas. Coordenador do Programa de Pós-Graduação em Educação - PPGE da Universidade Municipal de São Caetano do Sul, Coordenador do Curso de Pedagogia da Universidade Paulista. São Paulo - SP - Brasil mirandanonato@uscs.edu.br

Mateus Reis Santos Bolsistas Cnpq Programa de Iniciação Científica Ensino Médio. ETEC Jorge Street / Universidade Municipal de São Caetano do Sul. São Paulo - SP - Brasil mateustuxa@hotmail.com
\end{abstract}

Arcy Pires Piagetti Junior Mestrando em Educação na Universidade Municipal de São Caetano do Sul. Professor do Centro Paula Souza. São Paulo - SP - Brasil arcy.junior@etec.sp.gov.br

Resumo: o objetivo desta pesquisa foi identificar as motivações das escolhas profissionais de um grupo de adolescentes, bem como as intervenções do meio familiar nesse processo. Trata-se de uma pesquisa de natureza qualitativa realizada com adolescentes concluintes do Ensino Técnico de Nível Médio cujos resultados mostram que dentre os motivos que levaram as adolescentes a realizar a escolha profissional destaca-se a realização pessoal, mas o retorno financeiro esteve bastante presente, principalmente, na perspectiva das orientações parentais. A despeito da variedade de novas carreiras no mercado, esse aspecto não sobrepôs às carreiras mais tradicionais na hora da decisão das adolescentes, contudo, a influência familiar foi decisiva nesse processo. Ademais, a formação técnica de nível médio, segundo as participantes, não garante um bom emprego, é necessário ter um curso superior que facilitará a inserção delas no mercado de trabalho. Esse resultado permite fazer duas considerações: a) a preferência pela profissão em nível superior sobrepõe à de nível médio; b) a escolha da carreira continua tendo influência do núcleo familiar mesmo quando os adolescentes afirmam o contrário.

Palavras-chave: Adolescência. Ensino Técnico de Nível Médio. Escolha Profissional.

Abstract: the objective of this research was to identify the motivations of the professional choices of a group of adolescents, as well as the interventions of the family environment in this process. It is a qualitative research carried out with adolescents who completed the Secondary Technical Education whose results show that among the reasons that led the adolescents to make the professional choice stands out personal fulfillment, but the financial return was very present, especially from the perspective of parental guidance. Despite the variety of new careers on the market, this aspect did not overlap with the more traditional careers at the time of the adolescent's decision, however, the family influence was decisive in this process. In addition, the high school technical formation, according to the participants, does not guarantee a good job, it is necessary to attend an undergraduate course that will facilitate their insertion in the labor market. This result allows us to make two considerations: a) the preference for the profession at the higher level overlaps with the middle level; 
b) career choice continues to be influenced by the family nucleus even when adolescents claim otherwise.

Keywords: Adolescence. Secondary Technical Education. Choose Professional.

\section{Introdução}

A escolha profissional representa um momento crucial na vida do adolescente porque implica numa decisão que requer esboçar um projeto de vida, questionar valores, habilidades, bem como o que se gosta de fazer ou, até mesmo, o estilo de vida que se pretende ter (QUEIROZ; MOURA; VILLACHAN-LYRA, 2013). Esse cenário é desafiador para o adolescente cujo horizonte tende a agravar-se, na medida em que, "no contexto de trabalho contemporâneo" surgem "centenas de profissões, enquanto que muitas outras deixam de existir" (ALMEIDA; MAGALHÃES, 2011, p. 206).

Em geral, isso ocorre porque "A noção de trabalho configura-se não mais como uma progressão contínua e hierárquica dentro de uma organização, pois outras necessidades se impõem no mercado de trabalho" (ALMEIDA; MAGALHÃES, 2011, p. 206). Ademais, na perspectiva de Bauman, o mercado deixou de ser "aquela modernidade sólida e do capitalismo pesado" (BAUMAN, 2001, p. 76).

Esse panorama pode complicar a vida dos estudantes que, nem sempre, estão preparados para tomar decisões sérias porque, além de jovens e com pouca iniciativa, ficam angustiados diante da escolha profissional ou, até mesmo, "deprimidos, estressados, com dificuldade para sair da casa dos pais e definir seu próprio caminho" (WEINBERG, 2001).

Para minimizar essa situação, seria necessário que os pais compreendessem que a escolha profissional se dá na adolescência, cujo período é marcado por muitas transformações pelas quais seus filhos passam. Em razão disso, precisariam considerar que, embora sejam inúmeros os fatores a considerar nesse momento, deve-se ter em mente que a "[...] escolha tem que trazer realização pessoal", já que "não adianta escolher uma profissão que garanta alta remuneração" se por trás disso vier o sacrifício para exercê-la (PEREIRA, [20-?], p. 2).

Diante do exposto, questiona-se: será que para ter sucesso, dinheiro e reconhecimento é, inevitavelmente, necessária a formação superior? Ou ainda, será que, ao escolher uma carreira, o estudante poderia optar por algo que, realmente, goste ou teria que tomar uma decisão com base em outros fatores?

Esses questionamentos são importantes porque é sabido que, famílias com uma carreira em comum, de advogados, por exemplo, ou as (famílias) de baixa renda, mas que 
têm integrantes bem-sucedidos profissionalmente, em geral, tendem a influenciar mesmo que, sutilmente, seus filhos na escolha profissional.

Nesse caso, frases como: "essa profissão dá dinheiro", "o que importa é o bolso" ou até mesmo "quem faz o que gosta está pobre, pois não ganha dinheiro algum" são ditas pelos pais, irmãos ou pessoas próximas aos adolescentes com o intuito de persuadi-los acerca da escolha profissional.

Grosso modo, essas pessoas dão esse tipo de conselho desconsiderando que a autorrealização pode ser mais importante do que o retorno financeiro, pois, se não houver prazer com relação à profissão escolhida, o adolescente poderá frustrar-se tanto profissional quanto pessoalmente.

Os fatores econômicos são importantes e o ideal é que não sejam desconsiderados na ocasião da escolha profissional (MELO, 1994), mas "é preciso estar atento ao fato de que a identificação que cada um possui com uma profissão é um fator determinante para que essa escolha seja feita de forma assertiva" (CHIOCCA; FAVRETTO; FAVRETTO, 2016, p. 21).

A despeito dos inúmeros estudos (YOUNG; FRIESEN; BORYCKI, 1994) e pesquisas (YOUNG et al. 2001), por exemplo, apontando as contribuições da família no processo de escolha profissional, há controvérsias acerca dessa participação.

Para Silva (1996), a escolha profissional do jovem reativa as escolhas dos pais, acarretando, assim, antigos conflitos que muitas vezes não foram superados. Esse momento pode ser encarado pelos pais como uma possibilidade de reparação das próprias escolhas. Isso sugere que o jovem seja o depositário de fantasias inconscientes da família e, dessa maneira, cabe-lhe realizar aquilo que a família não realizou ou mesmo dar continuidade às tarefas já desenvolvidas por eles (SILVA, 1996).

Ao tomar uma decisão sobre a sua carreira profissional, a reação da família do adolescente causa impactos, sejam eles positivos ou negativos, no próprio adolescente, sendo elas sutis ou não. Portanto, por mais que a escolha feita pelo filho não satisfaça a expectativa depositada pelos pais, o apoio deles é importante para o bom relacionamento familiar. Além disso, o suporte dos pais ajuda o adolescente, que nessa fase da vida, procura alguém para ter como suporte (GONÇALVES, 1998).

Contudo, a reação negativa dos pais diante da escolha profissional do filho pode acarretar afastamentos e brigas entre os membros da família o que, por sua vez, gera mais insegurança ao adolescente podendo, inclusive, levá-lo a procurar apoio com pessoas não qualificadas para esse fim. 
Assim, considerando as proposições ora apresentada, o objetivo desta pesquisa foi investigar as concepções de alunos do curso de Ensino Técnico Integrado ao Médio (ETIM) em Administração acerca da escolha profissional.

\section{Os Desafios do Adolescente diante da Escolha Profissional}

Os desafios do adolescente para escolher uma profissão são muitos porque "[...] o desenvolvimento de carreira ocorre de modo não linear ao longo da vida" já que essa escolha ocorre na "[...] adolescência, período da vida repleto de significativas alterações fisiológicas e psíquicas, bem como em termos de papeis sociais" (ALMEIDA; SILVA, 2011, p. 75).

$\mathrm{O}$ adolescente, em geral, se vê numa situação bastante angustiante porque não está amadurecido o suficiente para tomar uma decisão dessa natureza (MIRANDA, 2006; MIRANDA; TRUFEN; BARROS FILHO, 2007). Isso ocorre porque as variáveis que compõem esse tema demandam análise crítica (SILVA; PACHECO, 2016) sendo que, nem sempre, eles e suas famílias estão preparados para esse tipo de demanda.

Com relação à questão da 'vocação', na perspectiva psicanalítica, por exemplo, é sabido que, "O problema é bastante profundo, porque, em última análise, deve-se considerar por que as pessoas fazem alguma coisa, em lugar de não fazer nada" (BOHOSLAVSKY, 2015, p. 48). Ademais, se a escolha profissional diz respeito a um planejamento de vida, é oportuno destacar que ela se remete a projeções complexas já que o "futuro implica desempenhos adultos e se trata [...] de um futuro personificado" (BOHOSLAVSKY, 2015, p.28). Nesses termos, "as escolhas profissionais têm linhas de contorno específicas nas diferentes fases de vida do sujeito" sendo que, [...] "em se tratando do indivíduo adolescente, a projeção futura referenciada num adulto exerce influência em sua escolha presente" (SILVA; PACHECO, 2016, p.2).

Diante do exposto, questiona-se: o que se deve levar em conta na hora de se fazer uma escolha profissional? Seriam as habilidades individuais, os interesses, as expectativas sociais ou quem sabe, ceder às pressões feitas pelos pais e escolher aquela profissão que eles julgam promissora? Destaca-se que essa possibilidade não é incomum, conforme apontado na pesquisa de Santos (2005) que investigou o papel da família e dos pares na escolha profissional.

São raros os casos em que os adolescentes se preocupam em discutir e se informar com antecedência acerca de qual seria o melhor caminho a seguir. A maior parte deles 
prefere, em geral, adiar o problema para a última hora levando-os a desistir dos cursos escolhidos nos primeiros semestres (LEMANN, 1999).

Segundo Macedo (1998), isso pode ser evitado, pois o jovem pode enfrentar a questão da escolha profissional sem grandes sofrimentos. Para tanto, seria necessário entender como a escolha de uma profissão é feita; quais os instrumentos condutores para determinada profissão de que cada jovem dispõe e como poderiam ser avaliados os interesses, aptidões, competências e potencialidades de cada pessoa por ocasião de sua escolha profissional. Ademais, a história de vida do sujeito da escolha dever ser levada em consideração por entender que uma escolha profissional não é construída nem acontece de um momento para outro, ao contrário, solidifica-se com o tempo (MACEDO, 1998).

Do mesmo modo, Whitaker (1997) considera a escolha como algo inerente à pessoa e não como uma vocação no sentido de um chamado irresistível para uma determinada profissão, conforme sugerem alguns psicólogos. Para essa autora, existem aptidões, interesses, características de personalidade, atitudes, valores, oportunidades educacionais dadas pelo nível socioeconômico etc., que devem ser considerados nesse momento.

Deduz-se, portanto, que as características individuais devam ser consideradas na tomada de decisão pelo adolescente quando for optar por essa ou aquela profissão.

Além disso, o adolescente, para definir seu futuro profissional, precisa considerar a situação do mercado de trabalho, as expectativas de sua família, mas sem perder de referência suas preferências individuais (BORDÃO-ALVES; MELO-SILVA, 2008; LEVENFUS, 1997; NEIVA, 1999).

Não obstante, quando ocorre a escolha profissional, na maioria dos casos, os adolescentes não estão suficientemente maduros e, nem tampouco, emocionalmente e devidamente informados para escolher uma profissão que satisfará seus interesses (SANTOS, 2005), pois muitas vezes são vítimas de um sistema educacional que, em geral, é precário (LEHMAN, 1999). Ademais, é uma fase de mudanças biopsicossociais caracterizada por transições já que “[...] durante esse período, o jovem fica num estado de desequilíbrio [...]" (LARA et al., 2005, p. 57). Nesse mesmo período “A vida cotidiana apresenta-se como uma realidade interpretada pelos homens e subjetivamente dotada de sentido para eles na medida em que forma um mundo coerente” (BERGER; LUCKMANN, 2013, p.35).

Deduz-se, portanto que o adolescente faz escolhas considerando aquelas que tenham significado e que dialoguem com seus ideais, sobretudo as que lhe tragam sentido. Assim, apesar de entender que o adolescente não tenha total clareza sobre o contexto em que se insere, ele precisa compreender que é necessário "deixar a condição atual para trás para 
ocupar uma nova" posição na sociedade (SILVA; PACHECO, 2016, p. 1). Concorda-se com esses autores, para quem, desse modo, o jovem adere aos papéis que o levará a ser como esse ou aquele adulto a quem valoriza e com o qual se identifica.

\section{Percurso Metodológico}

Esta pesquisa se caracteriza como qualitativa porque envolve abordagens interpretativas e naturalísticas dos assuntos. O pesquisador qualitativo estuda coisas em seu ambiente natural, tentando dar sentido ou interpretar os fenômenos, segundo o significado que as pessoas lhe atribuem (DENZIN; LINCOLN, 1994, p.2). Ademais, o estudo dos problemas da pesquisa, nesse caso, aborda "os significados que os indivíduos atribuem a um problema social ou humano" (CRESWELL, 2014, p.49-50).

Os dados foram coletados por meio de entrevista semiestruturada realizada com cinco estudantes do sexo feminino da $3^{\text {a }}$ série do ETIM em Administração de um colégio de São Caetano do Sul cujo tamanho da amostra foi definido pelo método da saturação que, segundo Glaser; Strauss (1967) apud Fontanella; Ricas; Turato (2008, p.18), originalmente consiste na "constatação do momento de interromper a captação de informações (obtidas junto a uma pessoa ou grupo) pertinentes à discussão de uma determinada categoria dentro de uma investigação qualitativa sociológica".

Por sua vez, a avaliação da saturação teórica a partir de uma amostra foi feita por um processo contínuo de análise dos dados, começado já no início do processo de coleta. Tendo em vista as questões colocadas aos entrevistados, que refletem os objetivos da pesquisa, essa análise preliminar buscou o momento em que pouco de substancialmente novo aparecesse, considerando cada um dos tópicos abordados (ou identificados durante a análise) e o conjunto dos entrevistados (FONTANELLA; RICAS; TURATO, 2008).

\section{A Escolha Profissional em Discussão}

Com relação à escolha profissional, das cinco entrevistadas, apenas uma não tinha, à época, uma decisão formada sobre o assunto. As demais desejam seguir carreira em nível superior (economia, direito, arquitetura, comunicação social).

A opção por dar continuidade aos estudos em nível superior deu-se porque, na concepção das participantes $(\mathrm{P})$, esse nível de ensino é mais especializado e cria melhores condições para a inserção futura, no mercado de trabalho. Em geral, elas compararam a 
formação em nível superior com a recebida em nível médio, conforme o depoimento apresentado a seguir:

[...] os cursos técnicos facilitam muito a vida das pessoas para arrumar um emprego bom (sic), mas não é como um curso superior que faz uma pessoa se especializar no que ela quer; o curso técnico é mais focado no emprego; eu não gostaria de ficar somente com o curso técnico, en quero fazer um curso superior (P1).

Destaca-se que a opção por um curso de nível superior pode estar atrelada ao retorno financeiro já que, no Brasil, a taxa de retorno da educação é relativamente elevada, da ordem de 12,9\%, tendo declinado desde o final da década de 1970 (MENEZES-FILHO, 2001 apud BARTALOTTI; MENEZES-FILHO, 2007). Não obstante, esses autores advertem que inúmeros estudos têm apontado que o comportamento das taxas de retorno da educação varia consideravelmente dependendo do nível educacional, de acordo com a oferta e demanda relativas por mão-de-obra dos diferentes níveis possíveis de instrução.

Isso induz pensar que o ensino superior traga um retorno financeiro maior que a formação em nível médio porque "[...] a educação superior, ao contrário dos níveis anteriores, tem um caráter mais profissionalizante e é subdividida em diversos cursos" (BARTALOTTI; MENEZES-FILHO, 2007, p. 488).

Essa perspectiva dialoga com a opinião dessa participante: "[...] no Brasil, principalmente, você precisa ter um curso que te deixa mais estável e o ensino superior é o minimo que as empresas estão pedindo, então você precisa ter o curso superior e vários cursos técnicos, não apenas o curso técnico" (P2).

Se por um lado, as exigências por formação em nível superior são muitas, por outro, o retorno financeiro para quem tem esse nível de formação é grande e diferenciado por cursos (NARITA; FERNANDES, 2001). Cada especialidade desenvolvida no ensino superior parece possuir demanda e oferta específica (BARTALOTTI; MENEZES-FILHO, 2007).

Esse ponto de vista corrobora a fala dessa participante que vê o assunto da seguinte forma: "para você seguir uma carreira, não pode ficar somente com o conbecimento técnico, tem que fazer alguma coisa em ensino superior; superior é uma coisa bem importante se você quer progredir na vida" (P.3).

A despeito do reconhecimento do curso técnico de nível médio, o ensino superior ainda é visto como solução para facilitar a inserção profissional no mercado de trabalho. Ocorre que "O técnico te ajuda a entrar no mercado de trabalho mais cedo; mas o ensino superior te dá mais capacidade para fazer o que quiser [...] eu acho que o ensino superior é um pouco melhor...” (P3) que o médio, opina uma estudante. 
Com relação à influência familiar sobre a escolha profissional, a pesquisa mostra que esse fenômeno ocorre direta ou indiretamente, mas não há ressentimento por parte dos participantes que veem isso como uma forma de orientação importante, conforme ilustrado nesse depoimento:

[...] primeiramente eu disse que queria fazer sociologia, mas meus pais me pediram para pegar (sic) alguma coisa que pelo menos você possa ganhar dinheiro; eu peguei alguma coisa que tem pelo menos o mesmo bloco de matérias principais; como um pouco de matemática aplicada; porque ai eu consigo trabalhar em empresa, no setor público ou em pesquisa por isso escolhi economia (P1).

Destaca-se que esse tipo de intervenção, quando feito de forma harmônica, pode ser positivo. Portanto,

[...] para cobranças dos pais, por vezes declaradas e, em outros momentos, sutis e veladas, ressaltando que quando o vínculo pais-filhos é harmonioso e verdadeiro, as opiniões parentais são valorizadas e até aceitas, sem a mera submissão dos adolescentes e, então, a família é sentida como fonte de apoio e sustentação (ANDRADE, 1997 apud ALMEIDA; MELOSILVA, 2011, p. 78).

Contudo, às vezes, os pais mostram-se inseguros frente à escolha da carreira dos filhos cuja insegurança despertada neles pode repercutir na decisão dos adolescentes a exemplo do que ocorreu com uma das participantes da pesquisa que pretendia cursar sociologia, mas em decorrência da influência familiar escolheu economia (OLIVEIRA, 2005).

Em razão disso, essa participante entende que "[...] de certa forma tem apoio da família, mas de certa forma eles estão me cortando (sic) um pouco porque en queria mesmo é fazer sociologia porque não sou boa em exatas não" (P1).

Esse tipo de influência não é positivo podendo inclusive gerar frustrações futuras à adolescente em relação à escolha profissional. Ademais, foi desconsiderado que:

As crises vivenciadas pelo adolescente e sua família incluem oscilações em sua definição profissional, indagações quanto à escolha de uma profissão rentável e segura, mas que não satisfaz, ou a opção por uma atividade que atrai, mas que não traz estabilidade financeira (SANTOS, 2005, p. 59).

Essa situação induz pensar que, ao invés de influenciar sua filha a escolher um curso de nível superior que pudesse trazer estabilidade financeira, o ideal seria que eles (os pais) pudessem reviver seus próprios conflitos da adolescência e apoiá-la em sua escolha.

Grosso modo, pode-se afirmar que a influência familiar manifesta-se como fator determinante na escolha profissional, mas o apoio e o aconselhamento adequados não criam 
uma barreira entre pais e filhos como acontece quando há mais críticas do que apoio. Assim, a certeza do rumo a seguir se torna maior por parte do estudante tendo em vista que a decisão deu-se mais por consentimento do que por pressão.

Mas, por vezes, a opinião das famílias é ignorada em razão de que o adolescente desconsidera as orientações recebidas optando por uma profissão com base em suas concepções. Mas, isso é raro, pois, em geral, eles evitam o conflito, postergando a decisão, conforme essa fala:

[...] to (sic) pensando em fazer arquitetura, mas ainda não é certeza... [...] meus pais me apoiaram, mas preferiam que eu fizesse engenharia... [...] é porque engenharia além de ganhar mais dinheiro tem melhores condições de mercado, mas como ainda não é certeza eu apenas ignorei, ainda penso em fazer arquitetura (P4).

Nota-se, portanto, que essa futura arquiteta mesmo diante da alegação dos pais de que cursar engenharia seria mais rentável do que arquitetura, ela os contraria mantendo sua escolha pela arquitetura.

Não obstante, essa decisão não é definitiva já que ela sinalizou que ainda pensa em outras áreas, como nutrição e jornalismo.

Assim, enquanto nos exemplos anteriores os pais foram filtradores para seus filhos, seja de forma positiva ou negativa, para a futura advogada quem mais a influenciou, mesmo que de forma indireta, foi seu irmão que é formado em Direito e sócio de uma empresa de advocacia.

Em razão disso, ela verbaliza: "[...] pretendo seguir direito, porque en já tive uma base com meu irmão que é advogado, eu sempre me imaginei sendo uma advogada" (P5).

Em relação à variabilidade de profissões, apenas a participante que pretende cursar economia notou alguma diferença, afirmando que a "maior ramificação profissional" facilitou o processo de escolha, fazendo com que optasse por uma carreira que mais a agradasse. As demais não perceberam nenhuma influência nesse sentido, ou seja, a escolha profissional para elas foi algo desenvolvido com o tempo.

É oportuno destacar ainda que, para os participantes, o Curso Técnico de nível médio propiciou um conhecimento melhor sobre o mercado de trabalho sendo que, para a futura estudante de Comunicação, a disciplina de Marketing foi responsável pelo desencadeamento do interesse por Comunicação Social.

Indagadas sobre a escolha profissional nos níveis técnico e superior, as participantes sinalizaram dois aspectos que merecem destaque: o mercado de trabalho e o conhecimento. 
Com relação ao conhecimento adquirido no Curso Técnico Integrado ao Médio (ETIM), cabe frisar que as depoentes partem do pressuposto de que há equivalência entre os conteúdos ministrados nos níveis básico e superior. Esse ponto de vista está alicerçado nas concepções dos professores, pois pelo menos "é o que alguns professores falam" (P3). Ademais, para a maioria delas, o conhecimento técnico de nível médio adquirido pode facilitar o acesso do egresso do ETIM ao mercado de trabalho.

Contudo, elas consideram que "o mercado de trabalho tem exigido cada vez mais especialização" sendo necessário, portanto, "o ingresso no ensino superior". Além disso, "o ensino superior é o melhor meio de preparação para o mercado profissional porque um graduado tem mais chances" (emprego) e "melhores remunerações" (MELO, 1994) quando comparado ao ETIM (P1; P3).

\section{Conclusão}

O estudo realizado com estudantes do ETIM em Administração revelou que elas têm um bom conhecimento sobre o mercado de trabalho facilitando sua escolha profissional em nível superior.

Apesar de elas terem concluído o ensino médio e se tornado técnicas, ou seja, aptas ao ingresso no mercado de trabalho, o ensino superior é almejado pela maioria delas por entenderem que a formação em nível médio não é suficiente para o ingresso no mercado de trabalho.

Com relação à escolha profissional, a pesquisa aponta que a opinião dos pais mostrou-se preponderante sobre a decisão dos filhos seja por meio de apoio, aconselhamento ou até mesmo certa pressão. Assim, "Mesmo o indivíduo possuindo o sentimento de que escolhe livremente, a família exerce um papel fundamental nesse processo" (ALMEIDA; MAGALHÃES, 2011, p. 208). Não obstante, entende-se que por mais paradoxal que possa ser, os jovens, apesar da insegurança característica da fase adolescente em que se encontram, têm condições de fazer escolhas sejam elas orientadas ou não pela família.

\section{Referências}

ALMEIDA, F. H.; MELO-SILVA, L. L. Influência dos pais no processo de escolha profissional dos filhos: uma revisão da literatura. Psico-USF, v. 16, n. 1, p.75-85, jan./abr. 2011. 
ALMEIDA, M. E. G. G.; MAGALHÃES, A. S. Escolha profissional na contemporaneidade: projeto individual e projeto familiar. Revista Brasileira de Orientação Profissional, v. 12, n. 2, 205214, jul.-dez. 2011.

BARTALOTTI, O.; MENEZES-FILHO, N. A relação entre o desempenho da carreira no mercado de trabalho e a escolha profissional dos jovens. Econ. aplic., São Paulo, v. 11, n. 4, p. 487-505, out./dez. 2007.

BAUMAN, Z. Modernidade Líquida. Rio de Janeiro: Jorge Zahar, 2001.

BERGER, P. L.; LUCKMANN, T. A construção social da realidade: tratado de sociologia do conhecimento. Tradução de Floriano de Souza Fernandes. 35. ed. Petrópolis, Vozes, 2013.

BORDÃO-ALVES, D. P.; MELO-SILVA, L. L. Maturidade ou imaturidade na escolha da carreira: uma abordagem psicodinâmica. Avaliação Psicológica, v. 7 n. 1, p. 23-34, abr. 2008.

BOHOSLAVSKY, R. Orientação vocacional: a estratégia clínica. 13. ed. São Paulo: Martins Fontes, 2015.

CHIOCCA, B.; FAVRETTO, L. H.; FAVRETTO, J. Escolha profissional: fatores que levam a cursar uma segunda graduação. ReCaPe Revista de Carreiras e Pessoas, São Paulo, v. VI, n. 1, jan./fev./mar./abr. 2016.

CRESWELL, J.W. Investigação qualitativa e projeto de pesquisa: escolhendo entre cinco abordagens. 3. ed. Porto Alegre: Penso, 2014.

DENZIN, N. K.; LINCOLN, Y. S. Handbook of qualitative research. London, Sage Publication, 1994. 
FONTANELLA, B. J. B.; RICAS, J.; TURATO, E. R. Amostragem por saturação em pesquisas qualitativas em saúde: contribuições teóricas. Cad. Saúde Pública, Rio de Janeiro, 24(1):17-27, jan. 2008.

GONÇALVES, C. M. A influência da família no desenvolvimento vocacional de adolescentes e jovens. Anais da $5^{a}$. Conferencia Bienal da EARA. Budapeste, Hungria, 1998.

LARA, L.D. et al. O adolescente e a escolha profissional: compreendendo o processo de decisão. Arq. Ciênc. Saúde Unipar, Umuarama, 9(1), p.57-61, jan./abr. 2005.

LEHMAN, I. P. Não sei que profissão escolher. São Paulo: Moderna, 1999.

LEVENFUS, R. S. Psicodinâmica da escolha profissional. Porto Alegre-RS: Artes Médicas, 1997.

MACEDO, R. B. M. Seu diploma, sua prancha: como escolher uma profissão e surfar no mercado de trabalho. 7. ed. São Paulo: Saraiva, 1998.

MELO, S. M. M. Orientação educacional: do consenso ao conflito. São Paulo: Papirus, 1994.

MIRANDA, N. A. Motivos da escolha profissional: um estudo com alunos calouros do curso de Pedagogia. Dissertação (Mestrado em Educação) - Universidade São Marcos, 2006.

; TRUFEM, S. F. B.; BARROS FILHO; J. Estudo comparativo acerca da escolha do curso de pedagogia em instituições particulares de São Paulo. Revista Ibero-Americana de Estudos em Educação, v. 2, n. 1, 2007.

NARITA, R.; FERNANDES, R. Instrução superior e mercado de trabalho no Brasil. Revista Economia Aplicada, São Paulo, v. 5, n. 1, p. 7-32, 2001.

NEIVA, K. M. C. Escala de Maturidade para a Escolha Profissional (EMEP): manual. São Paulo, SP: Vetor, 1999. 
OLIVEIRA, I. M. D. A. De quem é o vestibular? Articulações entre a família e a escolha profissional. In: VASCONCELOS, Z. B.; OLIVEIRA, I. D. (Org.). Orientação vocacional: alguns aspectos teóricos, técnicos e práticos (p. 61-77). São Paulo: Vetor, 2005.

PEREIRA, C. M. G. A escolha profissional do adolescente frente às demandas familiares e ao mercado de trabalho atual. [20-?]. Disponível em: $<$ http://www.eduvale.br/colegio/imprimir.php?id_editoria=\&id=528>. Acesso em: 12 dez. 2016.

QUEIROZ, E. F. F.; MOURA, R. B.; VILLACHAN-LYRA, P. Escolha da profissão: principais influencias pontuadas por estudantes do $2^{\circ}$ e $3^{\circ}$ ano do ensino médio. Anais do XIII Jornada de Ensino, Pesquisa e Extensão - JEPEX 2013 - UFRPE: Recife, 09 a 13 de dezembro. Disponível em: < http://www.eventosufrpe.com.br/2013/cd/resumos/R11121.pdf>. Acesso em: 10 set. 2017.

SANTOS, L. M. M. O papel da família e dos pares na escolha profissional. Psicologia em Estudo, Maringá, v. 10, n. 1, p. 57-66, jan./abr. 2005.

SILVA, L. B. C. A escolha da profissão: uma abordagem psicossocial. São Paulo: Unimarco, 1996.

SILVA, J. E.; PACHECO, M. M. D. Escolha da profissão do adolescente: pré-teste. Revista Científica On-line Tecnologia - Gestão - Humanismo, v. 7, n. 2, nov. 2016.

WEINBERG, C. (Org.). Geração delivery. São Paulo: Sá editora, 2001. Disponível em: $<$ http://www.saeditora.com.br/catalogo/geracao-delivery-adolescer-no-mundo-atual/>. Acesso em: 15 dez. 2016.

WHITAKER, D. Escolha da carreira e globalização. 11 ed. São Paulo: Moderna, 1997.

YOUNG, R. A. et. al. Career development in adolescence as a family project. Journal of Counseling Psychology, v. 48, n. 2, 2001, 190-202. http://dx.doi.org/10.1037/0022-167.48.2.190 
YOUNG, A. R.; FRIESEN, J. D.; BORYCKI, B. Narrative structure and parental influence in career development. Journal of Adolescence, n. 17, 173-191, 1994.

recebido em 19 out. 2017 / aprovado em 02 out. 2018

Para referenciar este texto:

MIRANDA, N. A.; SANTOS, M. R.; JUNIOR, A. P. P. A escolha profissional na perspectiva do estudante do ensino técnico de nível médio. Dialogia, São Paulo, n. 30, p. 133-146, set. /dez. 2018. Disponível em: < https://doi.org/10.5585/Dialogia.n30.8005> 